\title{
A New Model of Early Intervention Based on The Osteopathic Integrated Approach: Clinical Experience About 530 Newborn Monica Filisetti ${ }^{,{ }^{*}}$, Donatella Cattarelli ${ }^{1}$ and Stefano Bonomi ${ }^{1,2, *}$
}

${ }^{1}$ Pediatric and Neonatology Department. ASST del Garda. Desenzano del Garda Hospital, Brescia, Italy ${ }^{2}$ Osteopathic Center San Vigilio. Lonato del Garda, Brescia, Italy

\section{Publication History:}

Background: Newborns at risk for developmental impairment need a specific follow-up for early diagnosis and Received: April 01, 2019 adequate intervention. During the first year of life neural plasticity is at its highest; this is the most appropriate Accepted: June 10, 2019 time for an effective intervention, in order to promote healthy relationships and good experiences. Osteopathy is a manual therapy based on the evaluation and soft mobilization of the musculoskeletal and fascial systems in order to improve posture and motor skills. Some studies support its scientific value and safety for children undergoing osteopathic treatments.

Materials and Methods: We present clinical data collected during the experience at the program for Osteopathy, Early "Neurodevelopmental Follow-up and Pediatric Osteopathy" at Desenzano del Garda Hospital (Italy). It's a intervention, public health service in which osteopathy has been included in a perspective of Osteopathic Integrated Early Intervention.

The program, covering the first years of life, is dedicated to newborns at risk for developmental impairment and consists in:

1. Pediatric and neurological examination

2. Osteopathic evaluation and treatment performed by physicians skilled in traditional pediatric osteopathy, following the teachings of Doctor Viola M. Frymann

3. Home program to promote child development. A program that involves parents to create a good environment, to improve parent-child relationship and to support motor and sensory development during home activities.

Aim of the present study is to review clinical data of babies followed at the program and to describe their neurological development.

Results: The program takes care of more than 500 newborns.

Patients have been sent to the program from the Neonatology Department and the Territorial Services.

Average age at the first evaluation is 2 months.

Children followed at the program present the following conditions: prematurity, dystocia or hypoxia, postural and orthopedic disorders, congenital syndromes and neurological problems, gastrointestinal functional disorders. When necessary, medical advice from other specialists is requested, in a multidisciplinary perspective. The recommended integrated approach has proved to be very helpful in many aspects: postural setting, motor behavior, neuromotor development, gastrointestinal functions, relationship parent-child. Families accepted the recommended follow-up program. No child has had any adverse effects.

Conclusions: Our experience encourages to explore the potential of osteopathy in neonatal and pediatric care. The Osteopathic Integrated Early Intervention could be considered a model for safe and effective early intervention in order to promote development in newborns at risk.

\section{Background}

Child development emerges as a complex, dynamic process resulting from a bidirectional interaction between the child and the environment [1-3].

This process requires the adequacy of intrinsic and extrinsic factors. The infant's neurologic system needs to be in a ready state to receive and process environmental input. The development of the human brain is a long-lasting process beginning in utero and extending throughout the first years of life [4].

In the first stage of life, the response of the child to the environment emerges as a behavior involving motor, sensory, relational and emotional attitudes.

\section{Risk conditions for developmental impairment}

Neurodevelopment may be negatively affected by the presence of well-known risk factors: premature birth, acute intrapartum hypoxiaischemia, genetic disorders and abnormalities, perinatal conditions such as seizures, hypoglicemia, jaundice and infection, exposure to toxins, poor or inadequate perinatal care. Developmental disorders often are caused by the interaction of many related conditions [1,5-8].

*Corresponding Author: Dr. Monica Filisetti, Pediatric and Neonatology Department. ASST del Garda. Desenzano del Garda Hospital, Brescia, Italy; E-mail: monica.filisetti@gmail.com

*Corresponding Author: Dr. Stefano Bonomi, Osteopathic Center San Vigilio. Lonato del Garda, Brescia, Italy; E-mail: bonomistefano@libero.it

Citation: Filisetti M, Cattarelli D, Bonomi S (2019) A New Model of Early Intervention Based on The Osteopathic Integrated Approach: Clinical Experience About 530 Newborn. Int J Pediatr Neonat Care 5: 154. doi: https://doi. org/10.15344/2455-2364/2019/154

Copyright: (C) 2019 Filisetti et al. This is an open-access article distributed under the terms of the Creative Commons Attribution License, which permits unrestricted use, distribution, and reproduction in any medium, provided the original author and source are credited. 
Citation: Filisetti M, Cattarelli D, Bonomi S (2019) A New Model of Early Intervention Based on The Osteopathic Integrated Approach: Clinical Experience About 530 Newborn. Int J Pediatr Neonat Care 5: 154. doi: https://doi.org/10.15344/2455-2364/2019/154

Page 2 of 8

Cerebral palsy is described as the most common physical disability in childhood and occurs in 1 every 500 live births. The complete causal path to cerebral palsy is unclear in approximately $80 \%$ of cases, but risk factors are often identifiable from the history of the child, regarding conception, pregnancy, birth and the postneonatal period [9].

Preterm birth is commonly defined as any birth before 37 completed weeks of gestation, and the number of preterm births has increased since 1990. The preterm birth rate is about $10 \%$ and worldwide nearly 15 million infants are born prematurely annually $[1,10]$. These children often experience significant health problems (respiratory illnesses, feeding difficulties, frequent hospitalizations) [1,11-13]. Preterm babies are at risk for neurodevelopmental disorders. 5\% to $15 \%$ of preterm children will suffer from cerebral palsy. More than $50 \%$ show minor developmental disabilities such as motor, cognitive, learning, neuropsychosocial and behavioral impairment [14].

Early onset disorders consist of abnormal movement patterns, transient dystonia, postural instability, neurosensory impairments, visual problems, coordination disorders and minor neurological dysfunctions. Although these signs are often subtle, they may affect various aspects of child development such as language, attention, memory, visual spatial processing, and executive functioning [15-18]

\section{Evidence of early intervention}

An early intervention following hospital discharge is important to support optimal outcome in children at risk for developmental impairment $[11,12]$. Adequate follow-up is crucial for an early and accurate diagnosis. Children at risk for developmental disorders should be identified by the age of 6 months $[7,8]$.

Early interventions from birth to the age of 18 months, when the brain is highly plastic, could optimize the development of the central nervous system during this critical period [8,19-21]. Outpatient follow-up should be initiated immediately after discharge or recommended to take place within 1 to 2 months [15].

Brain development and refinement continue postnatally, driven by motor cortex activity. Early active movements are essential because infants who do not actively use their motor cortex risk to lose their cortical connections and dedicated functions. Furthermore, there is increasing evidence that the infant's motor behavior, through interaction with the environment, promotes growth and development of musculoskeletal structures as well as drives the ongoing development of the neuromotor system [8].

Neural networks change in response to environmental stimuli, so the structural and functional architecture of the brain changes, a process called neuroplasticity. Neuroplasticity is a lifelong process, and during the first years of life the child's brain is highly sensitive and adaptable to environmental input, causing rapid changes in neural connectivity [ 1-23].

Some systematic reviews shows the effectiveness of early interventions based on a program that enhances parent-infant interactions, provides optimal environment for learning, promotes motor, social and cognitive skills within an enriched environment $[12,24,25]$. Evidence suggests that early high quality parent-infant interactions positively influence cognitive and social development in children and reduce stress, anxiety and depression in parents $[11,12,14]$.

\section{Value of the osteopathic approach}

Osteopathic medicine is a manual therapy based on gentle manipulations of the musculoskeletal system. Scientific basis of osteopathy is the accurate knowledge of anatomy and physiology of the human body.

The founder of osteopathic medicine is Andrew Taylor Still (18281917), a physician who practiced in North America (Kansas and Missouri) [26]. The original American School of Osteopathy was founded in 1892 in Kirksville (Missouri), where one of the most important Universities of Medicine and Osteopathy is still existing (A.T. Still Osteopathic Medical University). Nowadays the teachings and practice of osteopathy are expanding throughout the whole world.

William Garner Sutherland (1873-1954), student of Dr. Still, expanded the osteopathic principles to the cranial field and focused his attention on the relationship between cranio-vertebral structures and the functioning of the nervous system [27].

The application of traditional osteopathy to children is possible thanks to the work and dedication of Doctor Viola M. Frymann (19212016), physician, founder of the Osteopathic Center for Children in San Diego (California), an international point of reference for neonatal and pediatric osteopathy.

The science of osteopathy is based on the following principles:

1. Structure and function are related. The primary function of the structure is motion, fundamental to all other body functions. Structural integrity will allow freedom of inherent physiological motion of the musculoskeletal system. This condition supports the efficient functioning of all other body systems, especially of the nervous system.

2. The whole body is a dynamic unit of function; each body part depends on each other. The fascia provides continuity to the musculoskeletal structure. Osteopathic medical philosophy promotes care for the whole individual; this care includes attention to the somatic components, but also to the interaction of the individual with the environment.

3. The body has in itself an inherent therapeutic potency and constant drive towards health. An example of that are the physiological mechanisms of self-regulation, and neural compensations. This capacity is enhanced following osteopathic manipulative treatment [28-30].

Pediatric osteopathy, according to the teachings and the model of Dr. Viola Frymann, requires specific competences and training to develop a specific sense of touch. Osteopaths have to be skilled at examining the soft tissues of the baby, at recognizing tissue texture abnormality, asymmetry and motion restriction. According to the teachings of Dr. Viola Frymann, pediatric osteopaths need to develop a perceptive sense of touch in order to recognize the proprioceptive behavior of tissues.

The osteopathic evaluation includes examination of posture and motor pattern: postural alignment, range and quality of movements in different body regions, symmetry of head and column, respiratory excursions of the thoracic region, structure and motion of cranial mechanism [28]. 
Citation: Filisetti M, Cattarelli D, Bonomi S (2019) A New Model of Early Intervention Based on The Osteopathic Integrated Approach: Clinical Experience About 530 Newborn. Int J Pediatr Neonat Care 5: 154. doi: https://doi.org/10.15344/2455-2364/2019/154

Page 3 of 8

A gentle perceptive palpation, appropriate to the delicate tissues of a newborn, can detect somatic dysfunction, which is defined as a restriction of movement of the tissues. Somatic dysfunction, listed in the International Classification of Diseases (ICD-10 Segmental and Somatic Dysfunction), is a restriction of movement in a part of the musculoskeletal system [31]. Somatic dysfunction can be consequence of delivery or of pathological conditions early in life.

Observation emphasizes the importance of the somatic system in the process of development. Aim of the osteopathic intervention is to remove, or reduce, the influence of somatic dysfunction in order to enable neurological development and support the child in reaching his/her optimum potential [32].

Osteopathic manipulative treatment consist in very delicate manipulations and soft mobilizations of the musculoskeletal structures. The objective of the treatment program is the restoration of unrestricted, symmetric, physiologic mobility of all body parts, aimed at improving postural setting and at enabling free and symmetrical movement [33].

Osteopathic treatment is customized. Each child has different clinical problems and unique structural and functional status. Therefore, every child needs a specific program of osteopathic treatment, which may be integrated with other treatments, if indicated [34].

Osteopathic manipulative treatment appears to be a safe treatment modality in the pediatric population, when administered by physicians skilled in pediatric osteopathy [35].

The main reasons for consultation are musculoskeletal and postural problems (es. plagiocephaly, and torticollis), and gastrointestinal functional disorders [36-41].

For children with neurological problems, osteopathy could be considered a complementary treatment in the rehabilitation program [32]. Osteopathic treatments have a potential role also in prevention by integrating them into primary care [34,42].

\section{Materials and Methods}

The program for "Neurodevelopmental Follow-up and Pediatric Osteopathy" was established at Desenzano del Garda Hospital in 2010. It's a public health service dedicated to newborns at risk for developmental disorders. Aim of the present study is to review clinical data of babies followed at the program and describe their neurological development.

The program offers a new model of early intervention based on an osteopathic integrated approach. The model has been developed following a personal training with Doctor Frymann. She has spent many years of her life taking care of children, especially the ones with neurological difficulties, in order to help them expressing their potential.

Newborns receive the first evaluation as soon as possible after discharge from the hospital and follow the program during their first years of life. The standard program includes appointments at ages of $2-3-6-12-18$ months. A customized program is defined, based on the specific needs of each child.

At each appointment the child receives:
1. pediatric examination, to evaluate general health, feeding, sleep rhythm and growth;

2. neurological assessment with careful regard to motor skills and progress in development;

3. osteopathic evaluation and treatment, performed by physicians skilled in traditional pediatric osteopathy;

4. consultation with parents to present the home program to promote child development.

Professionals who work at the program are physicians with a specific training in neurodevelopmental and pediatric rehabilitation. They are also osteopaths who followed a specific training with Doctor Viola M. Frymann at the Osteopathic Center for Children (San Diego, California).

When necessary, medical advice from other specialists is provided (neurologist, neurosurgeon, orthopedist) in a multidisciplinary perspective.

The basic foundations of the program are:

Neurodevelopmental evaluation, which consists in:

1. Postural assessment: Evaluation of postural control and stability, with particular attention to alignment and postural stability, tone, reflexes and neurovegetative status.

2. Observation of motor behavior: Gross/fine motor assessment includes identification of aberrant motor patterns, observation of visual tracking and patterns of reaching-and-grasping movements, observation of general movements quality, variability and fluidity.

3. Evaluation of stages of development, concerning motor, sensorial, relational and cognitive skills Aim of the accurate evaluation is also the early recognition of children who require specific rehabilitative programs.

\section{Osteopathic evaluation and treatment}

Osteopathic traditional approach, based on the teachings of Dr. Frymann, consists in very delicate evaluations and mobilizations of the musculoskeletal system (Figure 1). Aims of the treatments are:

1. to promote optimal motricity and establish functional movement patterns, taking into consideration that movement is a basic expression of the individual interacting with the environment. A good motor control is also necessary for gesture production [43-46].

2. to improve postural alignment and promote neurovegetative functions and stability. Postural stability supports neurovegetative functions such as sleep and nutrition. Premature infants show irregular sleep-wake rhythm because of brain immaturity and circadian rhythms disorders. Furthermore, more regular sleep patterns are associated with an increasing functional connectivity and neuromaturation [47-51].

3. surveillance, prevention and treatment of torticollis and plagiocephaly that could interfere with the developmental process. Postural plagiocephaly is frequent in preterm babies and is associated with delayed development [52]. The osteopathic approach is considered adequate for the treatment of positional plagiocephaly. 
Citation: Filisetti M, Cattarelli D, Bonomi S (2019) A New Model of Early Intervention Based on The Osteopathic Integrated Approach: Clinical Experience About 530 Newborn. Int J Pediatr Neonat Care 5: 154. doi: https://doi.org/10.15344/2455-2364/2019/154

Page 4 of 8

4. to support digestive functions and reduce functional gastrointestinal disorders such as constipation, gastroesophageal reflux, colic.

The final aim of the osteopathic treatment is to promote the wellbeing of the children and allow them better opportunities to interact with parents and the environment. A strong relationship between motor and cognitive areas has been noted.

\section{To promote child development}

Involving parents in a home program aimed to:

1. improve parent-child relationship. Parents are invited to be aware of the competences of their child, to find a channel of communication respecting the rhythms of the child and recognizing the needs of the baby. This includes sensitivity to children's movements, sound and gesture and interpreting and responding appropriately to them. Communicating face-toface with the child can support emotional experience, visual attention, postural adjustment and it is a good opportunity to interact. Early development of communication is the building block for cognitive processes, literacy and social interactions. Meaningful relationship with the baby provides nurturing care that promotes development.

2. to offer adequate opportunity for learning.

Parents are invited to create a good environment which provides essential infant directed sensory input and offers opportunities for the child to explore and build motor and communication skills.

Infant stimulation program involves multi-sensory stimulations such as auditory, visual, vestibular and tactile stimulations. Infant massage is also encouraged. If a delay in a specific area is detected, adequate suggestions are recommended to promote specific skills, during daily care activities and during play time (Figure 2).
The novelty of the program are:

1. A combination of pediatric evaluation, neurological assessment and osteopathic evaluation performed by the same physician allow a better global understanding of the baby development.

2. An integration between traditional pediatric osteopathy and an individualized program of exercise and stimulations for babies, designed to promote specific steps of neurological development, produces a better support to early brain development.

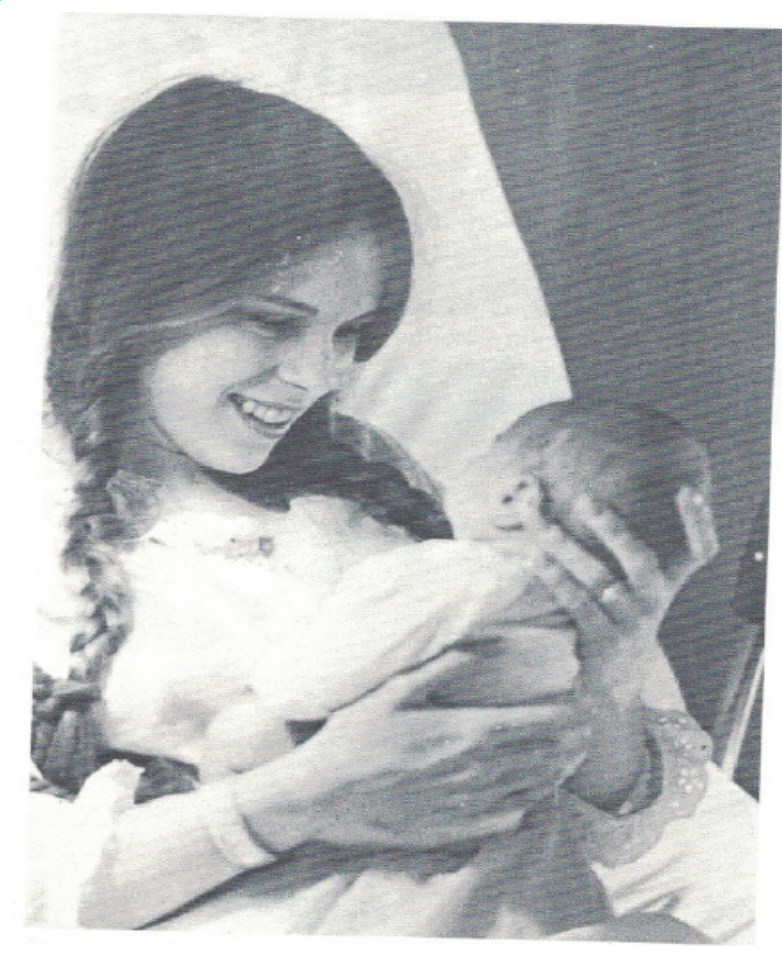

Figure 2 : Face-to face interaction it's a meaningful experience in the visual, relational, postural and emotional field [53].

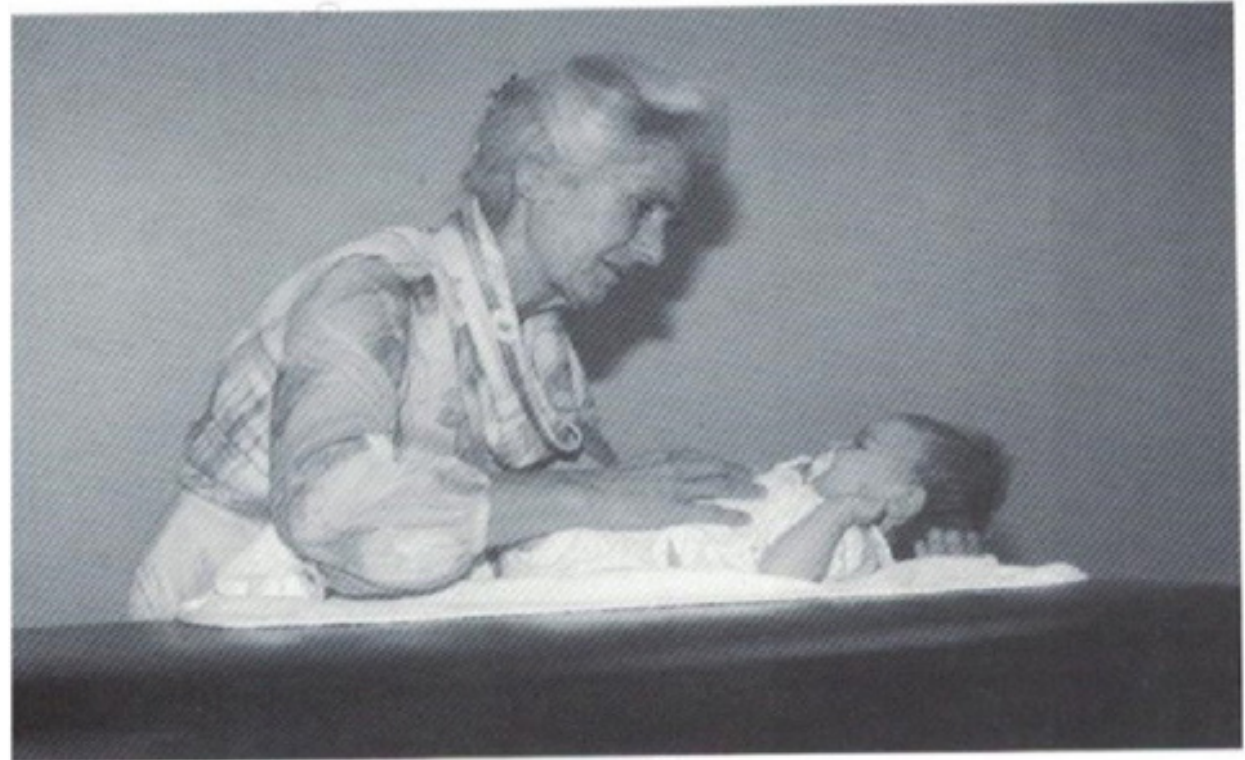

Figure 1 : Doctor Fymann treating a baby. 
Citation: Filisetti M, Cattarelli D, Bonomi S (2019) A New Model of Early Intervention Based on The Osteopathic Integrated Approach: Clinical Experience About 530 Newborn. Int J Pediatr Neonat Care 5: 154. doi: https://doi.org/10.15344/2455-2364/2019/154

Page 5 of 8

3. The program is supported by the public health system and integrated with all other services of the neonatological-pediatric department.

\section{Results}

During 8 years of experience, the program has taken care of 530 newborns.

We present ethnic origin and clinical characteristics of the babies.

\section{Sending services}

Patients have been sent to the program from

1. the Neonatology Department 227 babies (43\%)

2. Territorial Services 303 babies (57\%); Pediatrician 226 babies (43\%), and Neurologist 77 babies (14\%) (Figure 3)

\section{Early intervention}

The average age at first evaluation is 2 months of life, in accordance with recent indications regarding the most suitable age to recommend an early intervention.

\section{Multiethnicity}

Origin of the families is multiethnic (according to the Italian social landscape)

1. Italy (362 babies, $68 \%$ )

2. Other countries (168 babies, 32\%). East Europe: 35\%, Marocco and North Africa: 27\%, India and Pakistan: 22\%, Central and Southern Africa: 13\%, Cina: 3\%

\section{Reasons for consultation}

Children followed at the program presented the following conditions at first evaluation:

\section{Provenance}

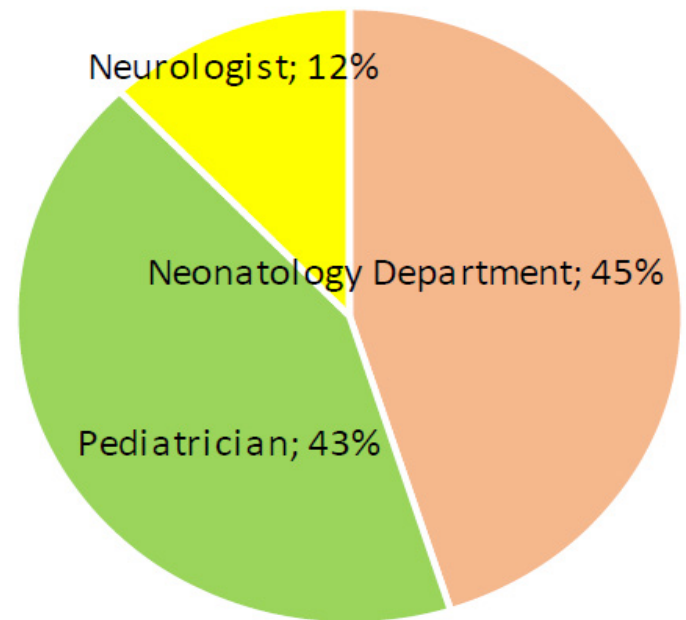

Figure 3: Provenance of children referred to the Service.

\section{Ethnic origins}

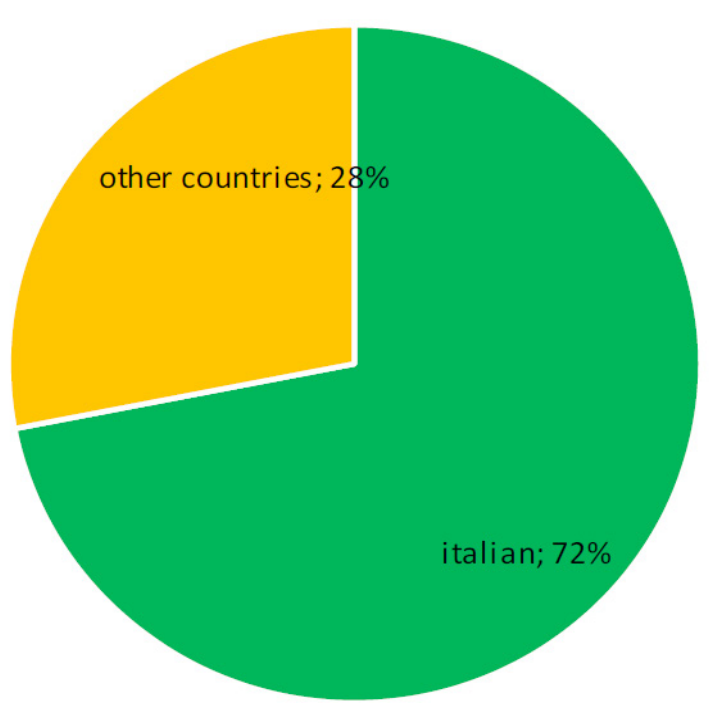

Figur 4 : Ethnic Origin of families. 
Citation: Filisetti M, Cattarelli D, Bonomi S (2019) A New Model of Early Intervention Based on The Osteopathic Integrated Approach: Clinical Experience About 530 Newborn. Int J Pediatr Neonat Care 5: 154. doi: https://doi.org/10.15344/2455-2364/2019/154

Page 6 of 8

1. Prematurity (185 babies, $35 \%$ )

2. Plagiocephaly (167 babies, $32 \%$ )

3. Postural and orthopedic disorders (torticollis, foot deformities, postural asymmetries) (45 babies, $8 \%$ )

4. Difficult delivery with dystocia or neonatal hypoxic-ischemic encephalopathy: (35 babies, 7\%)

5. Gastrointestinal functional disorders (gastroesophageal reflux, constipation): 34 babies (6\%)

6. Minor neurological disorders (hyperexcitability, hypotonia, hypertonia, tremors): (28 babies, $5 \%$ )

7. Congenital syndromes and neurological diseases (Down Syndrome, epilepsy neurological delay) (25 babies, $5 \%$ )

8. Others (sleep disorders, visual problems) (11 babies, $2 \%$ )

\section{Satisfaction and safety}

Families accepted the recommended follow-up program. The increasing number of patients sent to the program, shows its value and utility.

Each child received an average of 5 evaluations, for a total of more than 2500 session of osteopathic treatments. No child has had any adverse effects.

\section{Neurological development}

The babies received a neurological evaluation at the age of 12 and 18 months, performed by a pediatric neurologist. $98 \%$ of babies $(520$ babies) showed neurological development adequate to their age at 18 months and were discharged from the program. A few children (10 babies, 2\%) showed a delay in some areas of development. They received an early diagnosis and started a rehabilitation program at Territorial Services, which continued after the follow-up. Further evaluations are necessary to quantify the results.

\section{Discussion}

The purpose of this study is to share our clinical experience. The study has methodological limitations. The main limitation is the absence of a control group. Ethical consideration suggests that all newborns at risk should receive adequate treatment as soon as possible. Neurodevelopmental assessment is based on clinical and neurological evaluations and not quantified by using a neurological scale.

However some clinical consideration can be made. Neurological evaluations showed a positive influence on the developmental progress of children, with an improvement in motor skills and postural assessment.

According to the descriptive statistics of this experience, some clinical considerations emerge:

1. The model is supported by recent knowledge about child development and brain maturation

2. The program requires specific training for the physicians involved, particularly osteopathic treatment must be applied by experienced pediatric osteopaths

3. The proposed program is safe and not expensive and can be reproduced worldwide, even in countries with limited resources

\section{Conclusion}

Children at risk for neurodevelopmental impairment are increasing. Early diagnosis and early educational interventions are crucial to support optimal outcome for these vulnerable children. Many studies evaluated effectiveness of early intervention programs focusing on parent-infant relationship, environmental stimulation, care giving, meaningful experience, aimed to optimize neuroplasticity and promotethe infant's optimal development. So far no studies have considered the value of osteopathy in a program of early developmental intervention.

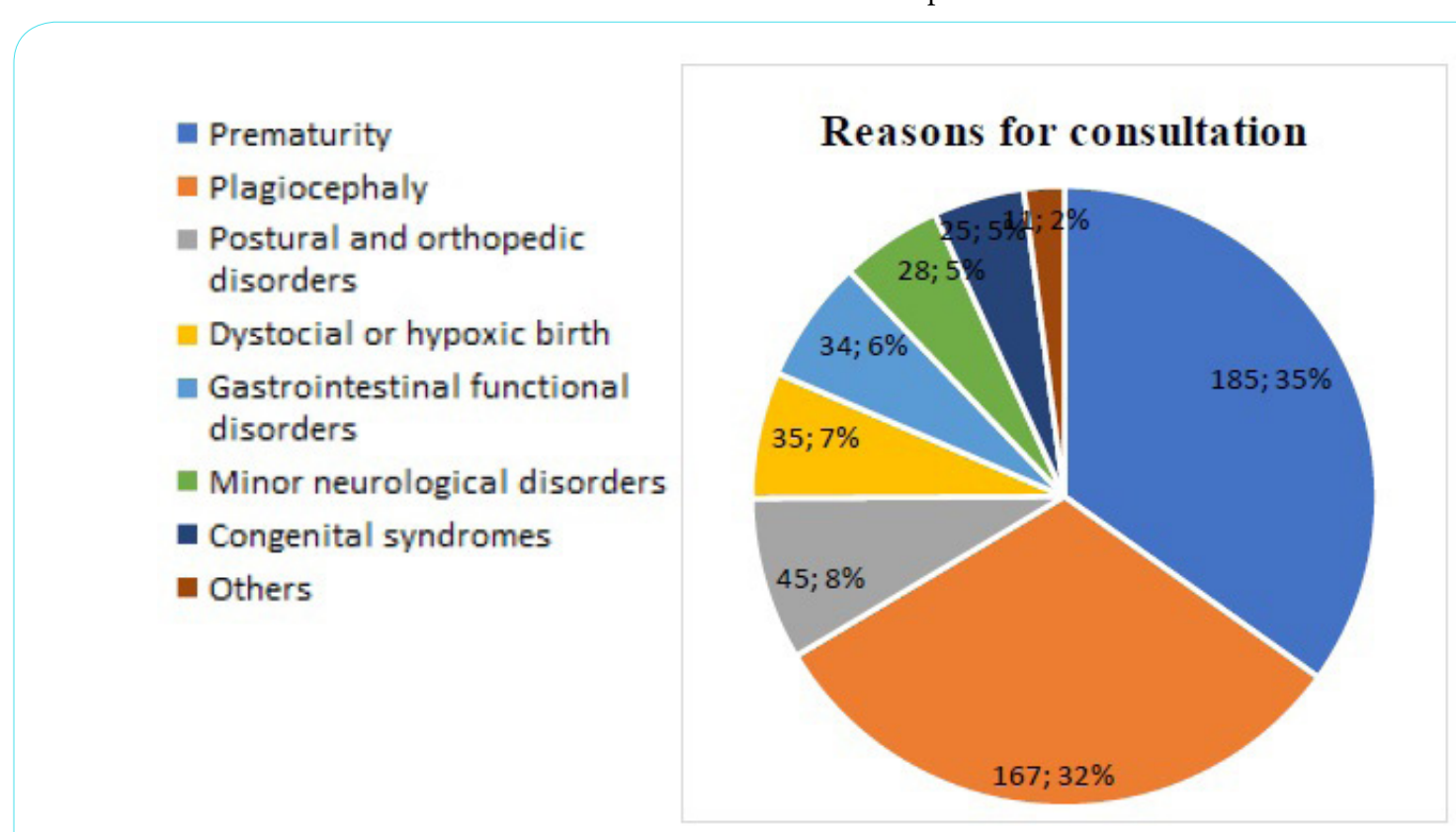

Figure 5 : Reasons for consultation. 
Citation: Filisetti M, Cattarelli D, Bonomi S (2019) A New Model of Early Intervention Based on The Osteopathic Integrated Approach: Clinical Experience About 530 Newborn. Int J Pediatr Neonat Care 5: 154. doi: https://doi.org/10.15344/2455-2364/2019/154

Page 7 of 8

The proposed model considers the potential of the osteopathic approach to support child development, and prepare the child to have the opportunity to learn at home through good relationships and adequate environmental stimulations.

Traditional osteopathic treatments, following the model of Doctor Frymann, is a safe treatment for children in early stages of life.

The program is appropriate to promote neurologic development and helpful for early diagnosis of babies with neurological impairment. The program is the first experience introduced in the Italian public health system that combines traditional osteopathy and a customized home program to promote development.

The osteopathic integrated approach could be considered a model of early intervention to promote development in newborns at risk.

Our experience encourages to explore the potential of an osteopathic approach in neonatal and pediatric care.

\section{Competing Interests}

The authors declare that they have no competing interests.

\section{Acknowledgements}

Authors thanks Dr. Viola Frymann for teachings and for encouragement to develop the program and explore the potential of osteopathy for children

\section{References}

1. Gormley JE, Williams DL (2019) Providing Supportive Hospital Environments to Promote the Language Development of Infants and Children Born Prematurely: Insights From Neuroscience. J Pediatr Health Care.

2. Adolph K, Franchak J (2017) The development of motor behaviorWiley Interdiscip Rev Cogn Sci.

3. Moriceau S, Sullivan R (2005) Neurobiology of Infant Attachment. Dev Psychobiol 47: 230-242.

4. Hadders-Algra M (2018) Early human motor development: From variation to the ability to vary and adapt. Neurosci Biobehav Rev 90: 411-427.

5. Biasone V, Rosa GD (2018) Early Prenatal and Perinatal Factors Related to Neurodevelopment: a Brief Overview. Int J Pediatr Neonat Care 4: 140.

6. Spittle AJ, Morgan C, Olsen JE, Novak I, Cheong JLY, et al. (2018) Early Diagnosis and Treatment of Cerebral Palsy in Children with a History of Preterm Birth. Clin Perinatol 45: 409-420.

7. Morgan C, Fahey M, Roy B, Novak I (2018) Diagnosing cerebral palsy in fullterm infants. J Paediatr Child Health 54: 1159-1164.

8. Novak I, Morgan C, Adde L, Blackman J, Boyd RN, et al. (2017) Early, Accurate Diagnosis and Early Intervention in Cerebral Palsy: Advances in Diagnosis and Treatment. JAMA Pediatr 171: 897-907.

9. Shapiro BK (2004) Cerebral palsy: A reconceptualization of the spectrum. Pediatr 145: 3-7.

10. Blencowe $H$, Cousens S, Jassir FB, Say L, Chou D, et al. (2016) National, regional, and worldwide estimates of stillbirth rates in 2015, with trends from 2000: a systematic analysis. Lancet Glob Health 4: 98-108.

11. Puthussery S, Chutiyami M, Tseng PC, Kilby L, Kapadia J, et al. (2018) Effectiveness of early intervention programs for parents of preterm infants: a meta-review of systematic reviews. BMC Pediatr 18: 223.

12. Spittle A, Orton J, Anderson PJ, Boyd R, Doyle LW, et al. (2015) Early developmental intervention programmes provided post hospital discharge to prevent motor and cognitive impairment in preterm infants. Cochrane Database Syst Rev 24: CD005495.
13. Moster D, Lie RT, Markestad T (2008) Long-term medical and social consequences of preterm birth. N Engl J Med 359: 262-273.

14. McGowan EC, Vohr BR (2019) Neurodevelopmental Follow-up of Preterm Infants: What Is New? Pediatr Clin North Am 66: 509-523.

15. Lipner HS, Huron RF (2018) Developmental and Interprofessional Care of the Preterm Infant: Neonatal Intensive Care Unit Through High-Risk Infant Follow-up. Pediatr Clin North Am 65: 135-141.

16. Dusing SC, Izzo TA, Thacker LR, Galloway JC (2014) Postural complexity differs between infant born full term and preterm during the development of early behaviors. Early Hum Dev 90: 149-156.

17. Dusing SC, Harbourne RT (2010) Variability in postural control during infancy: implications for development, assessment, and intervention. Phys Ther 90: 1838-1849.

18. Ferrari F, Gallo C, Pugliese M, Guidotti I, Gavioli S, et al. (2012) Preterm birth and developmental problems in the preschool age. Part I: minor moto problems. J Matern Fetal Neonatal Med 25: 2154-2159.

19. Cioni G, Inguaggiato $E$, Sgandurra $G$ (2016) Early intervention in neurodevelopmental disorders: underlying neural mechanisms. Dev Med Child Neurol 4: 61-66.

20. Hadders-Algra M, Boxum AG, Hielkema T, Hamer EG (2017) Effect of early intervention in infants at very high risk of cerebral palsy: a systematic review. Dev Med Child Neurol 59: 246-258.

21. Hadders-Algra M (2014) Early diagnosis and early intervention in cerebra palsy. Front Neurol 5: 185

22. Ismail FY, Fatemi A, Johnston MV (2017) Cerebral plasticity: Windows of opportunity in the developing brain. Eur J Paediatr Neurol 21: 23-48.

23. Johnston MV (2009) Plasticity in the developing brain: implications for rehabilitation. Dev Disabil Res Rev 15: 94-101.

24. Guralnick M (2011) Why Early Intervention Works A Systems Perspective Infants Young Child 24: 6-28.

25. Benzies KM, Magill-Evans JE, Hayden KA, Ballantyne M. (2013) Key components of early intervention programs for preterm infants and their parents: a systematic review and meta-analysis. BMC Pregnancy Childbirth 1: 10 .

26. Still AT (1892) The philosophy and mechanical principles of Osteopahy Kirksville, Missouri.

27. Sutherland WG (1990) Teachings in the science of osteopathy. SCT Foundation Editor. Texas.

28. Frymann VM (1998) The collected papers of Viola M. Frymann. Legacy of Osteopathy to Children. American Academy of Osteopathy. Indianapolis.

29. Frymann VM (1966) Relation of disturbances of craniosacral mechanisms to symptomatology of the newborn: study of 1,250 infants. J Am Osteopath Assoc 65: 1059-1075.

30. Frymann VM (1967) The expanding osteopathic concept. AAO Yearbook 67: 50-62.

31. ICD-10 (2016) International statistic classification of diseases and related Health Problems. WHO version.

32. Frymann VM, Carney RE, Springall P (1992) Effect of osteopathic medical management on neurologic development in children. J Am Osteopath Assoc 92: 729-744.

33. Philippi H, Faldum A, Schleupen A, Pabst B, Jung T, et al. (2006) Infantile postural asymmetry and osteopathic treatment: a randomized therapeutic trial. Dev Med Child Neurol 48: 5-9.

34. Frymann VM (1987) Cerebral dysfunction: prevention and treatment in the light of the osteopathic concept. Osteopathic Medical News.

35. Hayes NM, Bezilla TA (2006) Incidence of iatrogenesis associated with osteopathic manipulative treatment of pediatric patients. J Am Osteopath Assoc 106: 605-608.

36. Amiel-Tison C, Soyez-Papiernik E (2008) Cranial osteopathy as a complementary treatment of postural plagiocephaly. Arch Pediatr 1: 24-30.

37. Lessard S, Gagnon I, Trottier N (2011) Exploring the impact of osteopathic treatment on cranial asymmetries associated with nonsynostotic plagiocephaly in infants. Complement Ther Clin Pract 17: 193-198. 
Citation: Filisetti M, Cattarelli D, Bonomi S (2019) A New Model of Early Intervention Based on The Osteopathic Integrated Approach: Clinical Experience About 530 Newborn. Int J Pediatr Neonat Care 5: 154. doi: https://doi.org/10.15344/2455-2364/2019/154

Page 8 of 8

38. Sergueef N, Nelson KE, Glonek T (2006) Palpatory diagnosis of plagiocephaly. Complement Ther Clin Pract 12: 101-110.

39. Mills MV (2006) Consider osteopathic manipulation in next positional plagiocephaly research. J Pediatr 148: 706-707.

40. Snider KT, Snider EJ, DeGooyer BR, Bukowski AM, Fleming RK, et al. (2013) Retrospective medical record review of an osteopathic manipulative medicine hospital consultation service. J Am Osteopath Assoc 113: 754-767.

41. Morin C, Desrosiers J, Gaboury I (2017) Descriptive study of interprofessional collaboration between physicians and osteopaths for the pediatric population in Quebec, Canada. BMC Health Serv Res 17: 726.

42. Wainapel SF, Rand S, Fishman LM, Halstead-Kenny J (2015) Integrating complementary/alternative medicine into primary care: evaluating the evidence and appropriate implementation. Int J Gen Med 8: 361-372.

43. Kyvelidou A, Harbourne RT, Willett SL, Stergiou N (2013) Sitting postural control in infants with typical development, motor delay, or cerebral palsy. Pediatr Phys Ther 25: 46-51.

44. Hadders-Algra M (2004) General movements: A window for early identification of children at high risk for developmental disorders. J Pediatr 145: $12-18$.

45. Einspieler C, Prechtl HF (2005) Prechtl's assessment of general movements: a diagnostic tool for the functional assessment of the young nervous system. Ment Retard Dev Disabil Res Rev 11: 61-67.

46. Milani-Comparetti AM (1970) Pattern analysis of motor development and of its disorders. Psychiatr Neurol Med Psychol Beih 13-14: 41-49.

47. Dusing SC, Thacker LR, Galloway JC (2016) Infant born preterm have delayed development of adaptive postural control in the first 5 months of life. Infant Behav Dev 44: 49-58.

48. Dusing SC (2016) Postural variability and sensorimotor development in infancy. Dev Med Child Neurol 4: 17-21.

49. De Graaf-Peters VB, Blauw-Hospers $\mathrm{CH}$, Dirks $\mathrm{T}$, Bakker $\mathrm{H}$, Bos AF, et al (2007) Development of postural control in typically developing children and children with cerebral palsy: possibilities for intervention? Neurosc Biobehav Rev 31: 1191-1200.

50. De Graaf-Peters VB, De Groot-Hornstra AH, Dirks T, Hadders-Algra M (2006) Specific postural support promotes variation in motor behaviour of infants with minor neurological dysfunction. Dev Med Child Neurol 48: 966-972.

51. Fallang B, Hadders-Algra M (2005) Postural Behavior in Children Born Preterm. Neural Plast 12: 175-182.

52. Martiniuk AL, Vujovich-Dunn C, Park M, Yu W, Lucas BR, et al. (2017) Plagiocephaly and Developmental Delay: A Systematic Review. J Dev Behav Pediatr 38: 67-78.

53. Klaus M, Klaus P (1988) The Amazing Newborn. Published by Addison -Wesley Publishing Company. Massacchussets. 